\title{
Effect of single and double strap backpacks on lung function
}

\author{
S. J. LEGG $\dagger^{*}$ and C. O. CRUZ \\ $\dagger$ Centre for Ergonomics, Occupational Safety and Health, Department of Human \\ Resource, Massey University, Palmerston North, New Zealand \\ \$Division of Industrial Ergonomics, Department of Human Work Science, Luleå \\ University of Technology, Lulea, Sweden
}

Keywords: Load carriage; Schoolbag; Backpack; Lung function; Pulmonary ventilation; Respiration.

\begin{abstract}
Carrying heavy and moderate military loads in backpacks or as body armour compresses the chest, causing a change in lung function that is typical of a restrictive ventilatory impairment. It is not known if a lighter backpack load of only $6 \mathrm{~kg}$, such as is typical of loads carried by students, will have a similar effect on lung function. There have been no studies examining whether backpacks of different strapping styles have an effect on lung function. Several designs of student backpack have recently been introduced to the market. One of the most popular is a single-strap backpack. This study examined Forced Vital Capacity (FVC), Forced Expiratory Volume in one second $\left(\mathrm{FEV}_{1}\right), \mathrm{FEV}_{1} \cdot \mathrm{FVC}^{-1_{\%}}$ and Peak Expiratory Flow (PEF) in 13 participants (4 males, 9 females) wearing each of two $6 \mathrm{~kg}$ backpacks, one with two shoulder straps (a Double Strap Backpack (DSB)) and the other with a single strap (a Single Strap Backpack (SSB)) worn across the shoulder and chest. In comparison with the control of no pack $(\mathrm{N})$, SSB significantly reduced FVC (by $3.94 \%, p=0.006$ ) but there were no significant differences in $\mathrm{FEV}_{1}, \mathrm{FEV}_{1}$. $\mathrm{FVC}^{-1} \%$ and PEF. The DSB also significantly reduced $\mathrm{FVC}$ (by $1.97 \%, p=0.034$ ) but no significant differences were found in $\mathrm{FEV}_{1}, \mathrm{FEV}_{1}$. $\mathrm{FVC}^{-1} \%$ and PEF measures. In comparison with DSB, the SSB was associated with a significantly lower FVC (by $2.05 \%$, $p=0.049$ ) and $\mathrm{FEV}_{1}$ (by $1.88 \%, p=0.029$ ) but there were no significant changes in $\mathrm{FEV}_{1} . \mathrm{FVC}^{-1} \%$ and PEF. It is concluded that a backpack load of $6 \mathrm{~kg}$ could produce a mild restrictive type of ventilatory impairment in lung function. This effect was greater for a single cross-chest strap than for a more conventional double strap harness.
\end{abstract}

\section{Introduction}

Studies of load carriage have mostly concentrated on the metabolic and biomechanical changes associated with load weight, walking speed, gradient, terrain and other factors as well as medical hazards and performance limitations (see reviews by Haisman 1988 and Knapik et al. 1996). Soldiers often carry extremely heavy loads (McCaig and Gooderson 1986). Firefighters, mine rescue workers and other emergency personnel carry oxygen tanks for breathing apparatus in a

*Author for correspondence. Professor S J Legg, Centre for Ergonomics, Occupational Safety and Health, Department of Human Resource Management, Massey University, Private Bag 11222 , Palmerston North, New Zealand. e-mail: S.J.Legg@massey.ac.nz 
backpack frame system (Louhevaara et al. 1985, Smolander et al. 1985). Agricultural and forestry workers also often carry fertilizer or insecticide liquids containers on a backpack frame. Leisure or expeditionary hikers carry light day-packs or heavy alpine-style backpacks during recreational trail or mountain walking (Legg et al. 1997). Students in primary, secondary and tertiary education commonly use backpacks to carry their books and sporting equipment on a daily basis (Negrini et al. 1999, Grimmer et al. 1999, Grimmer and Williams, 2000, Whittfield et al. 2001, 2003).

There is, however, very little information on how the design, mass and mode of carriage of a backpack will affect the pulmonary ventilation of the user. Since the backpack frame, harness system and mass carried all oppose the expansion of the chest wall during inspiration, several studies have examined these effects and demonstrated that carrying heavy loads close to the trunk can affect lung function (Ghesquiere et al. 1979, Legg and Mahanty 1985, Epstein et al. 1987, Legg 1988, Muza et al. 1989). The changes in lung function are characterized by a restrictive type of ventilatory defect (Cotes 1979) in which Forced Vital Capacity (FVC) and Forced Expiratory Volume in one second $\left(\mathrm{FEV}_{1}\right)$ are reduced without a corresponding decrement in the $\mathrm{FEV}_{1} \cdot \mathrm{FVC}^{-1}$ ratio. It is possible that the respiratory restriction of the chest wall associated with load carriage could affect pulmonary ventilation during rest and exercise, resulting in the sensation of dyspnea and in arterial hypoxaemia, both of which could limit exercise capacity.

Legg and Mahanty (1985) reported a reduction in FVC, FEV F $_{1}$ and Maximum Voluntary Ventilation that could be sustained for $15 \mathrm{~s}\left(\mathrm{MVV}_{15}\right)$ by about $12 \%$ when a load equivalent to $35 \%$ of body weight (approximately $25 \mathrm{~kg}$ ) was carried on the trunk in the form of a weighted jacket. When the same weight was carried in the backpack, the corresponding decrements were 5,6 and 8\% respectively. Epstein et al. (1987) reported the same reduction in lung function indices with a $30 \mathrm{~kg}$ backpack load. Muza et al. (1989) also reported the same decrement pattern in lung function. This was related to the magnitude of the load, such that a $10 \mathrm{~kg}$ backpack reduced $\mathrm{FVC}$ and $\mathrm{FEV}_{1}$ by $3 \%$. Legg (1988) found that wearing military body armour also caused a mild restrictive decrement in lung function but questioned whether the mechanism was solely related to the weight of the load on the chest or trunk. He found a small reduction of $2-3 \%$ in $\mathrm{FVC}$, but a larger reduction of $10.4 \%$ in $\mathrm{MVV}_{15}$ associated with the lightest of three weights of body armour and suggested that tightness of fit may be important in determining these changes in lung function. Restrictive changes in lung function have been demonstrated with chest strapping (Ghesquiere et al. 1979, Caro et al. 1960) and the use of spinal immobilization devices (another form of chest strapping, Bauer and Kowalski 1988). Bygrave et al. (2003) showed that the effect of tightness of fit of backpack on lung function is additional to that of the weight of the load alone.

In the last few years, there has been concern about musculoskeletal discomfort and increasing low back pain amongst school students throughout the western world, but very little about university students. One of the contributory factors is the weight and mode of carriage of books, computers and associated paraphernalia. Lai and Jones (2001) have reported that a schoolbag load of heavier than $10 \%$ of a child's weight will have a restrictive effect on lung volumes but there have been no studies of the effects of different types of backpack strapping systems or harnesses.

A topic that has attracted somewhat less attention is the effect that the mode of load carriage that is used by students. This is surprising because there has been an 
explosion in variety and types of commercial backpacks for use by students. To the authors knowledge, only three commercial schoolbags have been developed with advice based upon ergonomics principles. These are the British National Back Pain Association (NBPA) schoolbag and the Australian PhysioPak and ChiroPak. These latter new schoolbags have only been recently been introduced to the world market and have both been manufactured by a single supplier, with advice from the University of South Australia Physiotherapy Department and the Chiropractic Association respectively. All of these are of a conventional style (backpack with two shoulder straps and a waist belt). A common and very recent popular design of schoolbag is one that has a single strap across the shoulder and chest. Numerous student backpacks of similar design are also available.

It is not known whether lung function is similarly affected with wearing a smaller and lighter schoolbag, nor whether there is any difference in lung function associated with different style (or strapping) of load carriage. The present study was therefore designed to determine whether a schoolbag weighted to $6 \mathrm{~kg}$ affects lung function and to determine if there is any difference in lung function associated with a conventional double strap backpack and a popular single strap (cross-chest) backpack harness.

\section{Methods}

\subsection{Participants}

Thirteen university students ( 4 males, 9 females), voluntarily participated in the study. Their mean (SD) physical characteristics were: age 27.3 (9.3) years, stature $163.3(8.5) \mathrm{cm}$ and body weight (BW) $66.3(13.3) \mathrm{kg}$. Their previous experience in backpack load carriage was mainly limited to leisure backpacking. None had any current respiratory problems, nor any prior history of respiratory illness. No formal medical screening was performed but a medical officer interviewed the participants prior to the study and assessed them as all being suitable to participate. Each volunteer was informed of the possible health hazards and risks of the study.

\subsection{Backpack}

A double strap backpack (DSB) and a single strap backpack (SSB) were used in the study. The DSB was a LiteAlp DayPack, Standard Size (MacPack Wilderness Equipment Company Ltd, New Zealand). Its strapping harness comprised two padded shoulder straps. The SSB was a Unistrap Body Bag NSP 770 (Rockfield Ltd, China). Its strapping harness comprised a single $5 \mathrm{~cm}$ wide strap worn across the shoulder and the chest, secured by Velcro. Each backpack was filled with books to obtain a total pack weight of $6 \mathrm{~kg}$. Participants were instructed to adjust the backpack to achieve a 'comfort fit' and given half an hour for familiarization with each backpack before the lung function tests were conducted.

\subsection{Lung function}

Lung function measurements were made according to standard methods (Cotes 1979) using a Vitalograph Single Breath Spirometer to determine FVC and $\mathrm{FEV}_{1}$, and a Wright Peak Flow Meter to determine peak expiratory flow (PEF) during maximally forced expirations, with the participants in an erect relaxed standing position and wearing comfortable clothing. The participants were given initial instruction and familiarization as a group on the techniques required and were also reminded before each testing procedure. They then provided three maximally forced 
expirations under each of the following three conditions: no backpack $(\mathrm{N})$, wearing the SSB and wearing the DSB. Thirty seconds was allowed between each maximal expiration and a minute of rest between each condition. The order of presentation of the conditions was according to a balanced randomized design. The highest value among the three attempts in each condition was used to compute the mean data for all subjects. Lung volumes and flows were corrected to body temperature and pressure of saturated gas (BTPS). One subject failed to undertake the PEF measurements due to personal reasons.

\subsection{Data analysis}

Analysis of variance (ANOVA) was used to identify significant differences between conditions for each of the lung function measurements. Statistically significant differences were accepted at a probability level of 0.05 . Post-hoc comparisons were used to identify the location of differences.

\section{Results}

The mean (SD) results are given in Table 1. In comparison with the control condition of no pack $(\mathrm{N})$, the single-strap backpack (SSB) significantly reduced FVC (by $3.94 \%, p=0.006$ ) but there were no significant differences in $\mathrm{FEV}_{1}$, $\mathrm{FEV}_{1} \cdot \mathrm{FVC}^{-1} \%$ and PEF. The double-strap backpack (DSB) also significantly reduced FVC (by $1.97 \%, p=0.034$ ) but no significant differences were found in $\mathrm{FEV}_{1}, \mathrm{FEV}_{1} \cdot \mathrm{FVC}^{-1} \%$ and PEF measures.

In comparison with the condition of wearing the DSB, the SSB was associated with a significantly lower FVC (by $2.05 \%, p=0.049$ ) and FEV1 (by $1.88 \%$, $p=0.029)$. There were no significant changes in $\mathrm{FEV}_{1} \cdot \mathrm{FVC}^{-1} \%$ and PEF.

\section{Discussion}

This study demonstrates that a backpack load of $6 \mathrm{~kg}$ influences lung function. The pattern of change in lung function characteristic of a mild restrictive ventilatory

Table 1. Effect of a single strap backpack (SSB) and double strap backpack (DSB) on lung function.

\begin{tabular}{|c|c|c|c|c|c|c|}
\hline & \multirow[b]{2}{*}{$\begin{array}{l}\text { No pack } \\
\text { (N) }\end{array}$} & \multirow{2}{*}{$\begin{array}{c}\text { Single strap } \\
\text { backpack } \\
\text { (SSB) }\end{array}$} & \multirow{2}{*}{$\begin{array}{c}\text { Double strap } \\
\text { backpack } \\
\text { (DSB) }\end{array}$} & \multicolumn{3}{|c|}{${ }^{\#}$ Percentage difference } \\
\hline & & & & $\begin{array}{c}\mathrm{SSB} / \mathrm{N} \\
(\%)\end{array}$ & $\begin{array}{c}\mathrm{DSB} / \mathrm{N} \\
(\%)\end{array}$ & $\begin{array}{c}\mathrm{SSB} / \mathrm{DSB} \\
(\%)\end{array}$ \\
\hline \multicolumn{7}{|c|}{$\mathbf{F V C}(\mathbf{l})(n=13)$} \\
\hline Mean & 3.55 & 3.41 & 3.48 & $3.94 *$ & $1.97 *$ & $2.05^{*}$ \\
\hline SD & 0.83 & 0.86 & 0.84 & $(p=0.006)$ & $(p=0.034)$ & $(p=0.049)$ \\
\hline \multicolumn{7}{|c|}{$\mathbf{F E V}_{\mathbf{1}}$ (l) $(n=13)$} \\
\hline Mean & 3.26 & 3.19 & 3.25 & 2.15 & 0.31 & $1.88^{*}$ \\
\hline SD & 0.85 & 0.84 & 0.80 & $(p=0.309)$ & $(p=0.840)$ & $(p=0.029)$ \\
\hline \multicolumn{7}{|c|}{$\mathbf{F E V}_{\mathbf{1}} . \mathbf{F V C}^{-\mathbf{1}_{\%}}(n=13)$} \\
\hline Mean & 91.53 & 93.58 & 93.34 & 2.24 & 1.97 & 0.27 \\
\hline SD & 5.21 & 4.78 & 4.12 & $(p=0.187)$ & $(p=0.232)$ & $(p=0.739)$ \\
\hline \multicolumn{7}{|c|}{ PEF $\left(\mathbf{l . s}{ }^{-1}\right)(n=12)$} \\
\hline Mean & 5.27 & 5.26 & 5.30 & 0.11 & 0.52 & 0.63 \\
\hline SD & 0.70 & 0.84 & 0.87 & $(p=0.918)$ & $(p=0.710)$ & $(p=0.461)$ \\
\hline
\end{tabular}

\#Percentage differences calculated as: $\mathrm{SSB} / \mathrm{N}=(1-\mathrm{SSB} / \mathrm{N}) \times 100, \mathrm{DSB} / \mathrm{N}=(1-\mathrm{DSB} /$ $\mathrm{N}) \times 100, \mathrm{SSB} / \mathrm{DSB}=(1-\mathrm{SSB} / \mathrm{DSB}) \times 100 . *$ Significance at $p=0.05$. 
impairment (reduced FVC and $\mathrm{FEV}_{1}$ but not in $\mathrm{FEV}_{1} \cdot \mathrm{FVC}^{-1_{\%}}$ ) was evident for both the SBP and the DBP, but although the fall in FVC was statistically significant, that in FEV1 was not. This finding is similar to that caused by wearing lightweight body armour (weighing less than $10 \mathrm{~kg}$ ) (Legg 1988) and is the first study to demonstrate an effect with such a light backpack load.

Lai and Jones (2001) reported that a schoolbag load heavier than $10 \%$ of a child's weight was associated with a restrictive effect on lung volumes. Other studies have recommended 10\% BW as the upper limit for schoolbag weight (Voll and Klimt 1977, National Back Pain Association 1997). In the present study the mean backpack load was 9.4\% BW (range 6.9-12.8) (with four of the 13 participants having a load greater than $10 \% \mathrm{BW}$ ). The findings therefore indicate that a similar but milder restrictive effect may be produced with a backpack load of less than $10 \%$ BW.

Caro et al. (1960), Ghesquiere et al. (1979) and Bauer and Kowalski (1988) have shown that chest strapping and spinal splinting produce a restrictive change in lung function in patients. The present study is, however, the first to demonstrate that the style of backpack strapping can also significantly affect lung function in a similar way, since there was clear and statistically significant evidence of greater chest restriction for SSB than for DSB. The single-strap backpack had a wide-strap that was worn across the chest and shoulders in a diagonal manner and appears to have produced a greater restrictive effect on the thorax, whereas the double-strap backpack had thinner straps attached over each shoulder, resulting in a lesser degree of restriction. An additional possible reason for this finding was that that some of the participants found that the strap of the SSB was too short for them so that they had difficulty in securing it firmly. Under these circumstances, it is possible that the effects observed may be due, at least in part, to tightness of fit similar to that reported by Bygrave et al. (2003). In the Bygrave study, patterns of changes in the indices of lung function that reflect flow in small airways were also reduced and associated with tightness of fit of the backpack harness. This suggested that a tightly fitting backpack could be associated with changes in lung function at the alveolar level. Since the present study has shown that the style of backpack strapping is associated with mild restrictive pattern of change in lung function, this may also be due to the tightness of fit that the style of backpack strapping presents. Thus, further studies examining the effect of the tightness of fit of the single-strap backpack harness on lung function, seem warranted. The use of single strap (cross-chest) backpack harnesses in walking, running and other more dynamic activities may have further effects on lung function.

In summary, this study has demonstrated a very small effect of a $6 \mathrm{~kg}$ backpack load on lung function characterized by a mild restrictive type of decrement. A single strap (cross-chest) backpack harness produced a greater restrictive effect than a more conventional double strap backpack harness. It is concluded that a double strap backpack loaded to $6 \mathrm{~kg}$ is associated with less restrictive change in lung function than a similarly weighted single strap backpack harness.

\section{References}

BaUer, D. and Kowalski, R. 1988, Effect of spinal immobilization devices on pulmonary function in the healthy non-smoking man, Annals of Emergency Medicine, 17, 915-918. 
Bygraye, S. J., Legg, S. J., Myers, S. D. and Llewellyn, M. 2004, Effect of backpack fit on lung function, Ergonomics, 47, 324-329.

Caro, C. G., Butler, J. and DuBois, A. B. 1960, Some effects of restriction of chest cage expansion on pulmonary function in man: an experimental study, Journal of Clinical Investigation, 39, $573-583$.

Cotes, J. E. 1979, Lung Function: Assessment and Application in Medicine (Oxford: Blackwell Scientific Publications).

Epstein, Y., Muza, S. R., Latzka, W. A. and Pandolf, K. B. 1987, Alterations in pulmonary function caused by a backpack load, Medicine and Science in Sports and Exercise, 19, 531.

Ghesquiere, J., Billiet, L., Reybrouck, T., Delamotte, G. and Vermiere, J. 1979, Limitation of work capacity by chest strapping in normal subjects, Bulletin European Physiopathologie Respiratoire, 15, 117.

Grimmer, K. and Williams, M. 2000, Gender-age environmental associates of adolescent low back pain, Applied Ergonomics, 31, $343-360$.

Grimmer, K., Williams, M. and Gill, T. 1999, The relationship between adolescent head on neck posture, backpack weight and anthropometric features, Spine, 24, 2262-2267.

Haisman, M. F. 1988, Determinants of load carrying ability, Applied Ergonomics, 19, 111 121.

Knapik, J., Harman, E. and Reynolds, K. 1996, Load carriage using packs: a review of physiological, biomechanical and medical aspects, Applied Ergonomics, 27, 207-216.

LAI, J. P. and JONES, A. Y. 2001, The effect of shoulder-girdle loading by a school bag on lung volumes in Chinese primary school children, Early Human Development, 62, 79-86.

LEGG, S. J. 1988, Influence of body armour on pulmonary function, Ergonomics, 31, 349-353.

Legg, S. J., Perko, L. and Campbell, P. 1997, Subjective perceptual methods for comparing backpacks, Ergonomics, 40, 809-817.

LegG, S. J. and Mahanty, A. 1985, Comparison of five modes of carrying a load close to the trunk, Ergonomics, 28, $1653-1660$.

Louhevaara, V., Smolander, J., Tuomi, T., Korhonen, O. and Jahkkola, J. 1985, The effect of SCBA on breathing pattern, gas exchange and heart rate during exercise, Journal of Occupational Medicine, 27, 213-216.

McCaig, R. H. and Gooderson, C. Y. 1986, Ergonomic and physiological aspects of military operations in a cold wet climate, Ergonomics, 29, 849-857.

Muza, S. R., Latzka, W. A., Epstein, Y. and Pandolf, K. B. 1989, Load carriage induced alterations of pulmonary function, International Journal of Industrial Ergonomics, 3, $221-227$

National Back Pain Association. 1997, NBPA school bag survey '97 -findings and recommendations (NBPA Newsletter), Talkback, 3, 3.

Negrini, S., Carabalona, R. and Sibilla, P. 1999, Backpack as a daily load for schoolchildren, Lancet, 354, 1974.

Smolander, J., Louhevaara, V. and Korhonen, O. 1985, Physiological strain in work with gas protective clothing in low ambient temperature, American Industrial Hygiene Association Journal, 46, $720-723$.

Voll, H. J. and Klimt, F. 1977, Strain in children caused by carrying schoolbags (author's transl), Das Offentliche Gesundheitswesen, 39, 369-378.

Whittfield, J., LegG, S. J. and Hedperley, D. I. 2001, The weight and use of schoolbags in New Zealand secondary schools, Ergonomics, 44, 819-824.

Whittfield, J., LegG, S. J. and Hedderley, D. I. 2003, Schoolbag weight and musculoskeletal symptoms in New Zealand secondary schools, Applied Ergonomics, (in press). 
Copyright of Ergonomics is the property of Taylor \& Francis Ltd and its content may not be copied or emailed to multiple sites or posted to a listserv without the copyright holder's express written permission. However, users may print, download, or email articles for individual use. 